\title{
Gamma knife surgery for brain metastases from ovarian cancer
}

\author{
Akiyoshi Ogino • Tatsuo Hirai • Takao Fukushima • \\ Toru Serizawa • Takao Watanabe • Atsuo Yoshino • \\ Yoichi Katayama
}

Received: 17 December 2011 / Accepted: 26 April 2012 /Published online: 16 May 2012

(C) The Author(s) 2012. This article is published with open access at Springerlink.com

\begin{abstract}
Background Brain metastases from ovarian cancer are rare, but their incidence is increasing. The purpose of this study was to investigate the characteristics of brain metastases from ovarian cancer, and to assess the efficacy of treatment with gamma knife surgery (GKS).

Methods A retrospective review was performed of patients with brain metastases from ovarian cancer who were treated at the Tokyo Gamma Unit Center from 2006 to 2010 .

Results Sixteen patients were identified. Their median age at diagnosis of brain metastases was 56.5 years, the median interval from diagnosis of ovarian cancer to brain metastases was 27.5 months, and the median number of brain metastases was 2. The median Karnofsky Performance Score (KPS) at the first GKS was 80 . The median survival following diagnosis of brain metastases was 12.5 months, and 6-month and 1-year survival rates were $75 \%$ and $50 \%$, respectively. The tumor control rate was $86.4 \%$. The KPS ( $<80$ vs $\geq 80)$ and total volume of brain metastases $\left(<10 \mathrm{~cm}^{3}\right.$ vs $\left.\geq 10 \mathrm{~cm}^{3}\right)$ were significantly associated with survival according to a univariate analysis $(p=0.004$ and $p=0.02$, respectively).
\end{abstract}

\footnotetext{
A. Ogino $(\bowtie) \cdot$ T. Fukushima $\cdot$ T. Watanabe $\cdot$ A. Yoshino

Y. Katayama

Department of Neurological Surgery,

Nihon University School of Medicine,

30-1 Oyaguchi-Kamimachi,

Itabashi-ku, Tokyo 173-8610, Japan

e-mail: akiyoshi@mvd.biglobe.ne.jp

T. Hirai $\cdot$ T. Serizawa

Tokyo Gamma Unit Center, Tsukiji Neurological Clinic,

Tokyo, Japan
}

Conclusions The results of this study suggest that GKS is an effective remedy and acceptable choice for the control of brain metastases from ovarian cancer.

Keywords Ovarian cancer · Brain metastases · Gamma knife surgery $\cdot$ Tumor control rate

\section{Introduction}

Ovarian cancer is one of the most frequently diagnosed gynecological malignancies [17]. Because symptoms are usually not noticed in the early stages, ovarian cancer tends to be diagnosed in the advanced stage and the prognosis, therefore, is generally poor. Brain metastases from ovarian cancer are rare, with their incidence ranging from $0.49 \%$ to $6.1 \%[3,6,7,9,14,15,20-22,24,25,34,37]$. However, recent studies have reported an increased incidence of brain metastases from ovarian cancer $[6,15,21]$. The primary reason for this increase is considered to be improvements in chemotherapy, which have led to better control of the primary malignancy and thus prolonged the life of the patients. In addition, early detection has been enabled by developments in imaging technologies $[4,12,26]$. Because gamma knife surgery (GKS) for brain metastases has a high local control rate and is minimally invasive $[1,2]$, it is generally an effective remedy. Nevertheless, to our knowledge, there have only been a few case reports and small series studies of GKS for brain metastases from ovarian cancer, and its efficacy remains unknown. In this study, we investigated the characteristics of patients with brain metastases from ovarian cancer, assessed the efficacy of GKS for local tumor control, and analyzed prognostic factors affecting patient survival. 


\section{Materials and methods}

\section{Patients}

From March 2006 to January 2010, a total of 2603 patients with brain metastases were treated with GKS at the Tokyo Gamma Unit Center. The hospital's database was searched to identify those with brain metastases from ovarian cancer, and the 16 identified patients were found to have been treated with GKS a total of 31 times. One hundred and nineteen tumors were treated in 31 GKS operations. Diagnoses in all patients were made with gadolinium-enhanced magnetic resonance imaging (MRI) with or without contrast-enhanced computed tomography.

Stereotactic radiosurgery was performed with a Leksell Gamma Knife model C (Elekta Instruments, Stockholm). All patients underwent thin-slice gadolinium-enhanced MRI after placement of the Leksell Model G stereotactic frame (Elekta Instruments) and the treatment plans were created using GammaPlan (Elekta Instruments). The dose delivered to the margin of the tumor ranged from 10.1 to $22.32 \mathrm{~Gy}$ (median $20.0 \mathrm{~Gy}$ ). The maximum tumor dose ranged from 20.2 to 43.0 Gy (median 39.2 Gy).

After GKS, follow-up MRI was performed every 13 months. We assessed changes in tumor size with follow up MRI, and evaluated response to treatment with the Response Evaluation Criteria in Solid Tumors guideline [41]. At the 3 months following GKS, 66 of 119 tumors could be evaluated for tumor size, enabling an analysis of the relationship between tumor size and tumor control.

To assess the predictive factors for survival following diagnosis of brain metastases, the following characteristics were reviewed: age at diagnosis of brain metastases ( $<60$ years vs $\geq 60$ years), interval from diagnosis of ovarian cancer to brain metastases ( $<2$ years vs $\geq 2$ years), number of brain metastases at first GKS (single vs multiple), total volume of brain metastases at first GKS $\left(<10 \mathrm{~cm}^{3}\right.$ vs $\geq 10 \mathrm{~cm}^{3}$ ), Karnofsky Performance Score (KPS) at first GKS ( $<80$ vs $\geq 80$ ), and treatment for brain metastases (GKS alone vs combination therapy).

\section{Statistical analysis}

Statistical analysis was performed with a personal computer running Stat View J-5.0 software (Abacus Concepts, Berkeley, CA, USA). Survival was calculated from the date of initial diagnosis of brain metastases until the date of death or last contact. The Kaplan-Meier method was used to calculate survival distributions. Differences in survival were analyzed using a log-rank test; $p<0.05$ was considered significant.

\section{Results}

From March 2006 to January 2010, a total of 2,603 patients with brain metastases were treated with GKS at the Tokyo Gamma Unit Center; 16 (0.6\%) of these patients had brain metastases from ovarian cancer. Two patients were treated with whole-brain radiotherapy (WBRT) before GKS (cases 4 and 9), two underwent surgical resection before GKS (cases 6 and 10), one was treated with WBRT and surgical resection before GKS (case 12), and one was treated with stereotactic radiotherapy before GKS (case 5). Patient characteristics of 16 patients are shown in Table 1.

The median age of the patients diagnosed with ovarian cancer and brain metastases was 53 years (range, 38-73 years) and 56.5 years (range, 44-75 years), respectively. The median interval from diagnosis of ovarian cancer to brain metastases was 27.5 months (range, 0-84 months), and the median number of brain metastases was 2 (range, 118). At the time of first GKS, the median KPS was 80 (range, 50-100).

At last follow-up, six patients were alive and ten patients had died. The overall median survival from the time of first GKS was 9.5 months (range, 3-29 months), from diagnosis of brain metastases was 12.5 months (range, 4-34 months), and from diagnosis of ovarian cancer was 46 months (range, 14-97 months). The 6-month and 1-year survival rates from the time of diagnosis of brain metastases were $75 \%$ and $50 \%$, respectively. The 6 -month and 1 -year survival rates from the time of first GKS were $69 \%$ and $31 \%$, respectively.

At 3 months following GKS, 66 tumors could be evaluated for tumor size; 17 tumors were in complete remission (CR), 40 showed partial response (PR), 8 stable disease, and 1 progressive disease (PD). The tumor of PD became a PR by performing additional GKS. The tumor control rate ([CR + $\mathrm{PR}]$ /total number of tumors $\times 100$ ) was $86.4 \%$. When tumors were classified by size, namely $<10 \mathrm{~mm}, 10-20 \mathrm{~mm}, 20$ $30 \mathrm{~mm}$, and $>30 \mathrm{~mm}$, the tumor control rates were $89.7 \%$, $86.7 \%, 80.0 \%$, and $50.0 \%$, respectively. No tumor hemorrhaged after GKS.

A total of nine patients $(56.3 \%)$ were found to have new brain metastases during the follow-up period. The interval between the date receiving initial GKS and the date of appearance of a new distant lesion was calculated. The median new distant-lesion-free survival period was 4.5 months (range, $1-15$ months).

Age at diagnosis of brain metastases, interval to brain metastases, number of brain metastases at first GKS, and treatment for brain metastases were not associated with survival following brain metastases. The KPS at first GKS and total tumor volume at first GKS were associated with survival and were important predictors of survival according to a univariate analysis ( $p=0.004$ and $p=0.02$, respectively). 


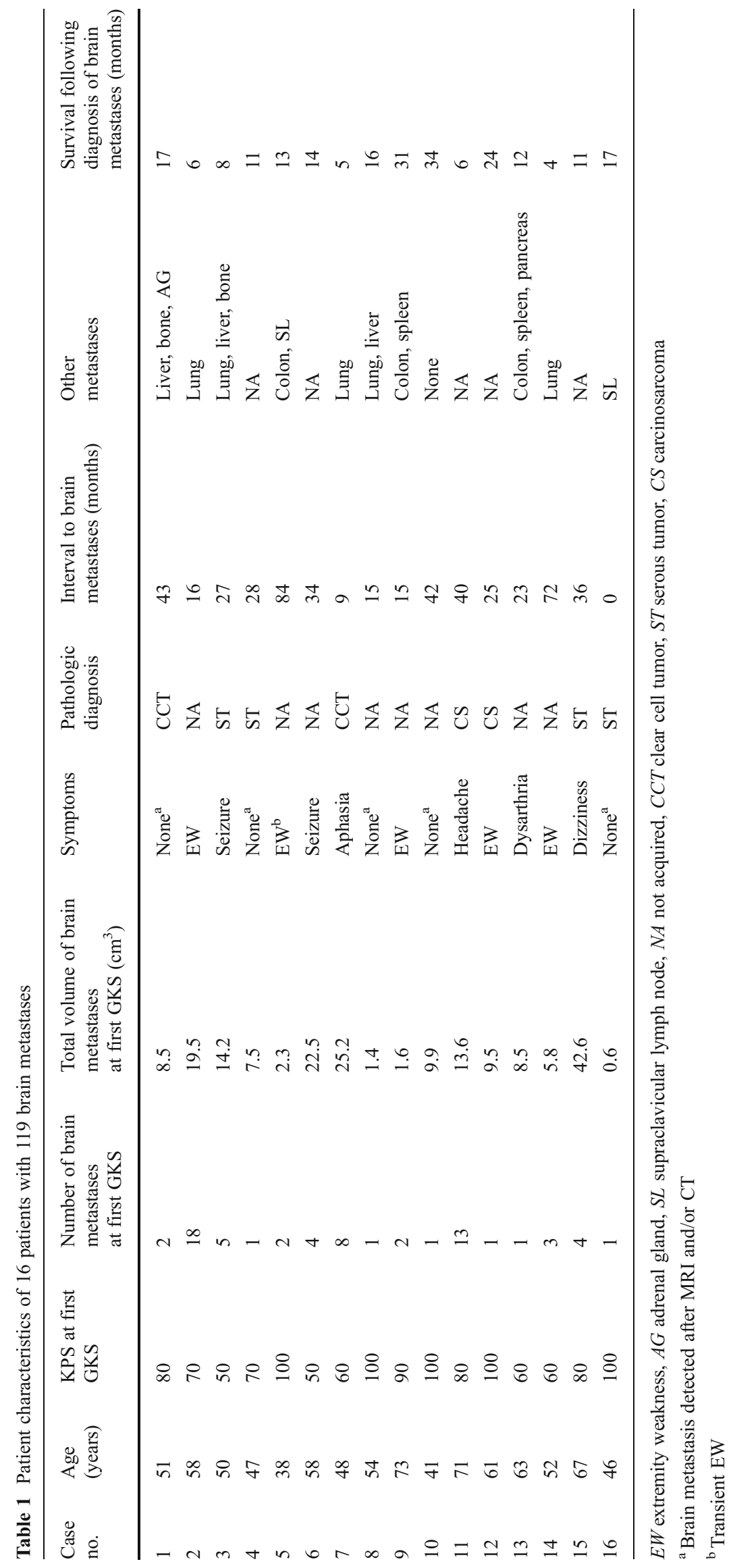


The median overall survival for the nine patients with KPS $\geq 80$ was significantly longer than that of the seven patients with KPS $<80$ (17.0 vs 8.0 months, $p=0.004)$. The median overall survival for the ten patients with total volume of brain metastases $<10 \mathrm{~cm}^{3}$ was significantly longer than that of the six patients with total volume of brain metastases $\geq 10 \mathrm{~cm}^{3}(16.5$ vs 7.0 months, $p=0.02$ ). The number of brain metastases was not significantly associated with survival, but the median overall survival for the six patients with a single metastases tended to be longer than that of the ten patients with multiple metastases (16.5 vs 9.5 months, $p=0.05$ ) (Table 2 ).

\section{Discussion}

Ovarian cancer is one of the most frequent causes of malignancy in women [17]. The majority of patients are discovered with advanced disease because very few symptoms are observed in the early stages of ovarian cancer. Brain metastases from ovarian cancer is uncommon-its incidence ranges from $0.49 \%$ to $6.1 \%[3,6,7,9,14,15$, 20-22, 24, 25, 34, 37]. Pectasides et al. [35] reported an estimated incidence of $1.01 \%$ in a review of 22,240 patients with ovarian cancer. However, recent studies have suggested that the incidence of brain metastases from ovarian cancer is increasing [6, 15, 21]. Platinumbased chemotherapy has led to improved survival rates among ovarian cancer patients, but these agents have poor blood-brain barrier permeability and brain metastases have thus become a late manifestation of ovarian cancer. The development of better imaging techniques has also enabled diagnosis on the basis of smaller brain metastatic lesions $[4,12,26]$.

In the review of brain metastases from ovarian cancer by Pectasides et al. [35], single brain metastases occurred in $43.8 \%$ of patients, multiple metastases in $51.6 \%$, and leptomeningeal metastases alone in $4.6 \%$. In this study, $37.5 \%$ of patients had single metastases, $62.5 \%$ had multiple metastases, and no patient had leptomeningeal metastases.

Data from the literature indicate that the median age at diagnosis of ovarian cancer ranges from 51 to 59.5 years, and the median age at diagnosis of brain metastases ranges from 52.5 to 58 years. The median interval to brain metastases ranges from 14.5 to 46 months $[3,5-7,9,14,15$, 20-22, 24, 25, 34, 37] (Tables 3, 4). The results from our patients support these data.

Brain metastases from ovarian cancer represent a late manifestation; once brain metastases occur, survival is generally poor, regardless of treatment $[14,21]$. Therapies for brain metastases include surgical resection, radiotherapy, chemotherapy, or their combination. Cohen et al. [7] reported that the combination of surgical resection and WBRT resulted in longer survival than WBRT alone or surgical resection alone (median survival of 23 months, 5 months, and 7 months, respectively). Anupol et al. [3] reported that combined treatment with radiation and surgical resection with or without chemotherapy led to a good prognosis in patients with brain metastases. Other authors have also supported an aggressive combination therapy approach
Table 2 Univariate analysis of survival following diagnosis of brain metastases

\begin{tabular}{|c|c|c|c|}
\hline Prognostic factor & $\begin{array}{l}\text { Number of } \\
\text { patients }\end{array}$ & $\begin{array}{l}\text { Median survival } \\
\text { (months) }\end{array}$ & $\begin{array}{l}\text { Log-rank } \\
p \text { value }\end{array}$ \\
\hline \multicolumn{4}{|c|}{ Age at diagnosis of brain metastases } \\
\hline$<60$ years & 10 & 12.0 & \multirow[t]{2}{*}{0.1841} \\
\hline$\geq 60$ years & 6 & 13.0 & \\
\hline \multicolumn{4}{|c|}{ Interval to brain metastases } \\
\hline$<2$ years & 6 & 14.0 & \multirow[t]{2}{*}{0.5592} \\
\hline$\geq 2$ years & 10 & 12.0 & \\
\hline \multicolumn{4}{|c|}{ Number of brain metastases at first GKS } \\
\hline Single & 6 & 16.5 & \multirow[t]{2}{*}{0.0507} \\
\hline Multiple & 10 & 9.5 & \\
\hline \multicolumn{4}{|c|}{ Total volume of brain metastases at first GKS } \\
\hline$<10 \mathrm{~cm}^{3}$ & 10 & 16.5 & \multirow[t]{2}{*}{0.0203} \\
\hline$\geq 10 \mathrm{~cm}^{3}$ & 6 & 7.0 & \\
\hline \multicolumn{4}{|l|}{ KPS at first GKS } \\
\hline$<80$ & 7 & 8.0 & \multirow[t]{2}{*}{0.0042} \\
\hline$\geq 80$ & 9 & 17.0 & \\
\hline \multicolumn{4}{|c|}{ Treatment for brain metastases } \\
\hline GKS alone & 10 & 9.5 & \multirow[t]{2}{*}{0.2020} \\
\hline Combination therapy & 6 & 19.0 & \\
\hline
\end{tabular}




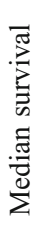

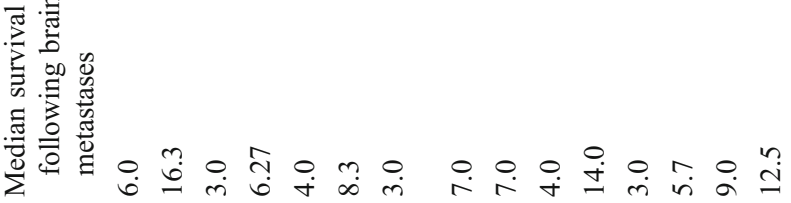

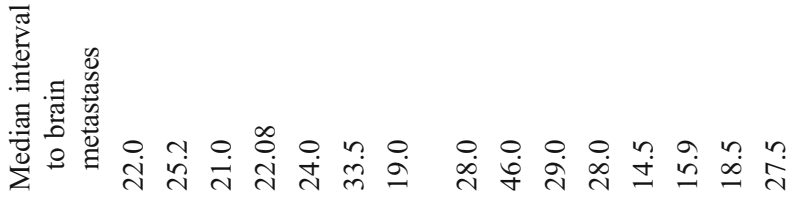

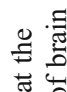

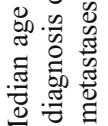

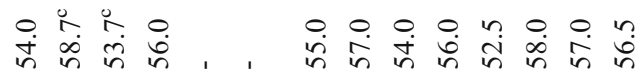

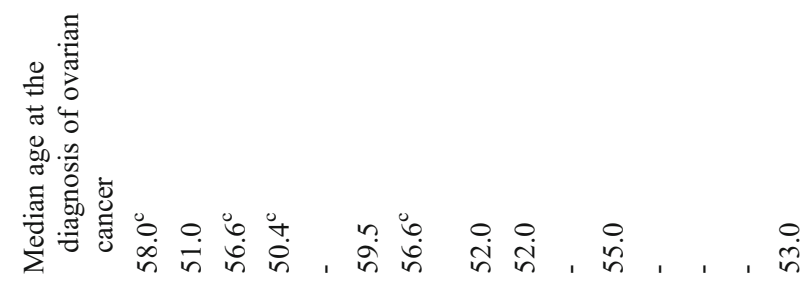

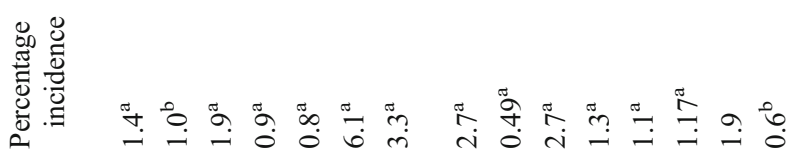

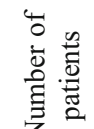

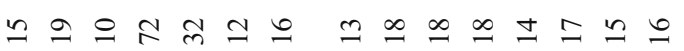

\&

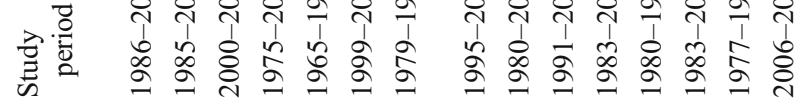

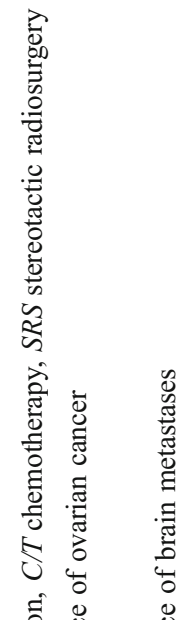

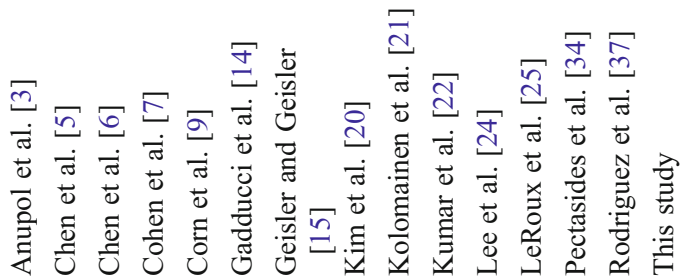

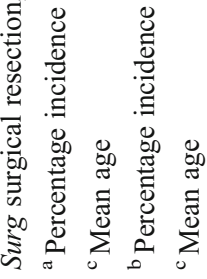




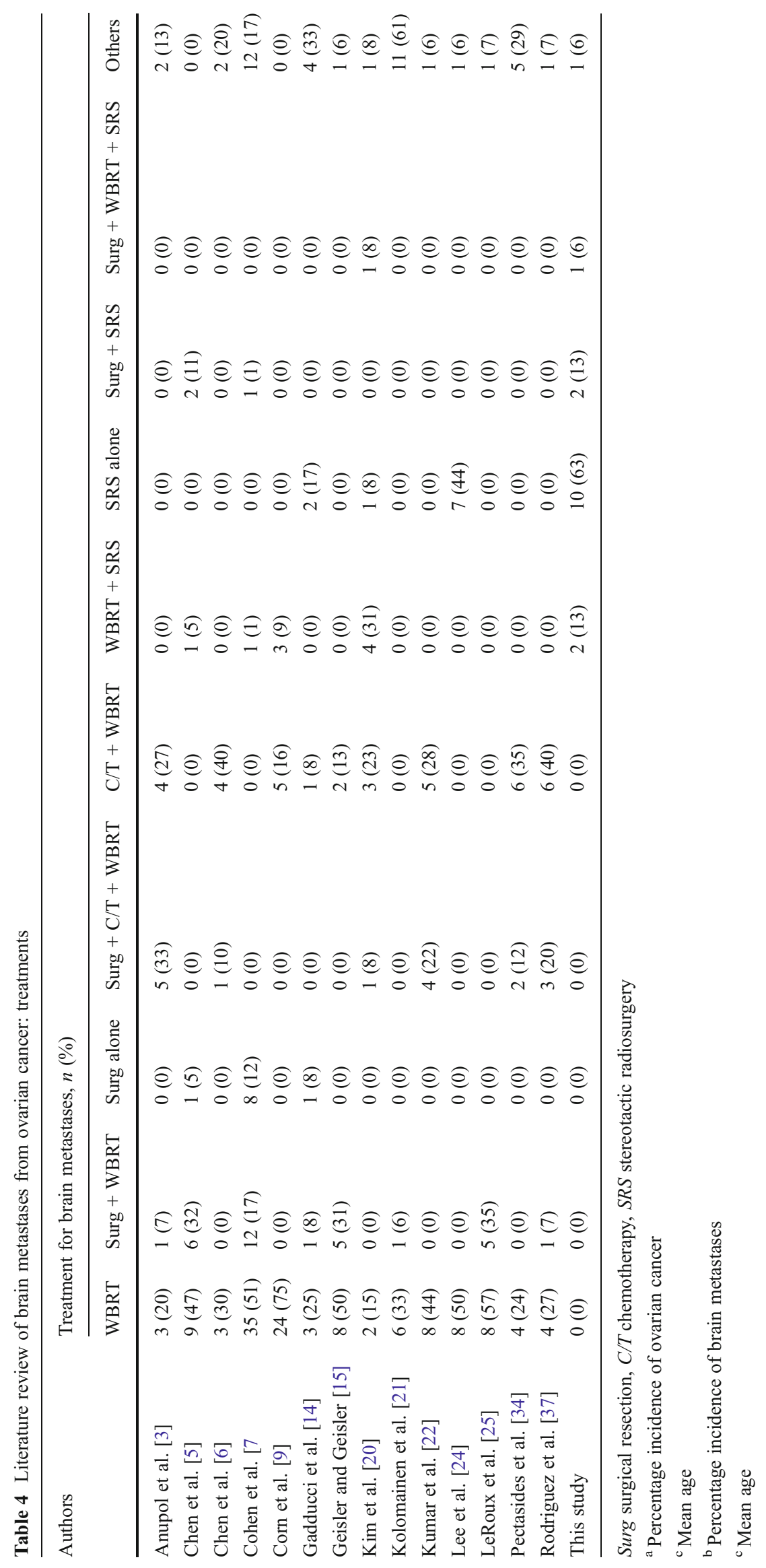


$[11,15,18,22,25,34,36,37]$. In our study, treatment for brain metastases was not significantly associated with survival, but the median overall survival for the six patients treated with combination therapy tended to be longer than that of the ten patients treated GKS alone (19.0 vs 9.5 months, $p=0.2$ ). Our result also supports combination therapy.

The efficacy of systemic chemotherapy for brain metastases from ovarian cancer remains controversial. Cooper et al. [8] reported a response in three patients with brain metastases treated with carboplatin, Melichar et al. [27] reported a response in a patient treated with cisplatin and gemcitabine, and Watanabe et al. [42] reported a response in a patient treated with carboplatin and docetaxel. To our knowledge, the only literature providing support for the efficacy of chemotherapy for brain metastases from ovarian cancer are case reports and small case series.

GKS for brain metastases has become increasingly common because GKS is a noninvasive modality that provides good local control [1, 2]. Muacevic et al. [30] reported that there were no significant difference in a 1-year local tumor control rate and 1-year survival rate between patients treated with GKS alone for solitary brain metastases and those who were treated with surgical resection plus WBRT. O'Neil et al. [32] reported that there was no significant difference in the 1-year survival rate between patients treated with GKS and those who underwent surgical resection (62\% vs $56 \%$ ), and GKS resulted in significantly better local control compared with surgical resection (recurrence rate of $0 \%$ vs $58 \%$ ).

GKS for brain metastases from ovarian cancer was first reported by Kawana et al. [19] in 1997. They described a case of multiple brain metastases successfully treated by a multimodality treatment including GKS. Lee et al. [24] reported that GKS for brain metastases from ovarian cancer resulted in longer survival compared with WBRT (median survival of 29 vs 6 months), and Corn et al. [10] reported that radiosurgery led to a more frequent complete remission (40\% vs $29 \%$ ), and higher 2-year survival rate (60\% vs $15 \%)$ than WBRT alone. Kim et al. [20] reported that treatment modalities including GKS were associated with survival and that patients with brain metastases had better outcomes with GKS. However, these reports are all from small series of patients and no prospective studies of GKS for brain metastases from ovarian cancer have been conducted. Our study is a retrospective study, but it is the second largest study of GKS for brain metastases from ovarian cancer to be performed. Monaco et al. [28] reported on 27 patients with brain metastases from ovarian cancer and endometrial carcinoma treated with GKS. The median survival after brain metastases was 7 months and the 1-year survival rate was $22 \%$. All tumors were controlled. They suggested that GKS was an acceptable choice for brain metastases, but their report included the results of the six patients with brain metastases from endometrial carcinoma.
In our study, the tumor control rate was $86.4 \%$ and no tumors hemorrhaged after GKS. Our results show tumor control rates comparable to those of lung cancers (72.7$94 \%)[16,33,38]$, breast cancers (90-94\%) [13, 23, 31], and renal cell cancer $(82.6-96 \%)[29,39,40]$. GKS for brain metastases from ovarian cancer provides good local control with few side effects.

Several reports have identified predictive factors for brain metastases from ovarian cancer. KPS, number of brain metastases, recursive partitioning analysis, and extracranial metastases have all been associated with survival $[3,5,9$, $18,20,25]$. In our study, the KPS $\geq 80 \%$ and total volume of brain metastases $<10 \mathrm{~cm}^{3}$ were factors to be significantly associated with longer survival $(p=0.004$ and $p=0.02$, respectively). Age at diagnosis of brain metastases, interval to brain metastases, number of brain metastases, and treatment for brain metastases were not associated with survival. However, patients with a single metastases tended to survive longer than patients with multiple metastases $(p=0.05)$.

Only a limited number of patients with brain metastases from ovarian cancer have been treated with GKS to date, and prospective data are lacking. However, the results of this study indicate that GKS for brain metastases from ovarian cancer provides good local control with few side effects. GKS thus appears to be an acceptable choice for the control of brain lesions in ovarian cancer patients. Combination therapy improves prognosis for patient with brain metastases from ovarian cancer. GKS can become one modality of combination therapy.

\section{Conclusions}

Brain metastases from ovarian cancer are rare, but their incidence is increasing as patient survival has been extended by successful platinum-based chemotherapy and improved imaging techniques have enabled the identification of smaller lesions. In our study, the median survival from brain metastases was 12.5 months, and the local control rate was $86.4 \%$. The KPS and total volume of brain metastases were important factors predictive of survival. Our results suggest that GKS is an acceptable therapy for brain metastases from ovarian cancer.

Conflicts of interest None.

Open Access This article is distributed under the terms of the Creative Commons Attribution License which permits any use, distribution, and reproduction in any medium, provided the original author(s) and the source are credited. 


\section{References}

1. Adler JR, Cox RS, Kaplan I, Martin DP (1992) Stereotactic radiosurgical treatment of brain metastases. J Neurosurg 76:444-449

2. Alexander E 3rd, Moriarty TM, Davis RB, Wen PY, Fine HA, Black PM, Kooy HM, Loeffler JS (1995) Stereotactic radiosurgery for the definitive, noninvasive treatment of brain metastases. J Natl Canc Inst 87:34-40

3. Anupol N, Ghamande S, Odunsi K, Driscoll D, Lele S (2002) Evaluation of prognostic factors and treatment modalities in ovarian cancer patients with brain metastases. Gynecol Oncol 85:487492

4. Bruzzone M, Campora E, Chiara S, Giudici S, Merlini L, Simoni C, Mammoliti S, Rubagotti A, Rosso R (1993) Cerebral metastases secondary to ovarian cancer: still an unusual event. Gynecol Oncol 49:37-40

5. Chen PG, Lee SY, Barnett GH, Vogelbaum MA, Saxton JP, Fleming PA, Suh JH (2005) Use of the Radiation Therapy Oncology Group recursive partitioning analysis classification system and predictors of survival in 19 women with brain metastases from ovarian carcinoma. Cancer 104:2174-2180

6. Chen YL, Cheng WF, Hsieh CY, Chen CA (2011) Brain metastasis as a late manifestation of ovarian carcinoma. Eur J Canc Care (Engl) 20:44-49

7. Cohen ZR, Suki D, Weinberg JS, Marmor E, Lang FF, Gershenson DM, Sawaya R (2004) Brain metastases in patients with ovarian carcinoma: prognostic factors and outcome. J Neurooncol 66:313-325

8. Cooper KG, Kitchener HC, Parkin DE (1994) Cerebral metastases from epithelial ovarian carcinoma treated with carboplatin. Gynecol Oncol 55:318-323

9. Corn BW, Greven KM, Randall ME, Wolfson AH, Kim RY, Lanciano RM (1995) The efficacy of cranial irradiation in ovarian cancer metastatic to the brain: analysis of 32 cases. Obstet Gynecol 86:955-959

10. Corn BW, Mehta MP, Buatti JM, Wolfson AH, Greven KM, Kim RY, Dunton CJ, Loeffler JS (1999) Stereotactic Irradiation: potential new treatment method for brain metastases resulting from ovarian cancer. Am J Clin Oncol 22:143-146

11. D'Andrea G, Roperto R, Dinia L, Caroli E, Salvati M, Ferrante L (2005) Solitary cerebral metastases from ovarian epithelial carcinoma: 11 cases. Neurosurg Rev 28:120-123

12. Dauplat J, Nieberg RK, Hacker NF (1987) Central nervous system metastases in epithelial ovarian carcinoma. Cancer 60:2559-2562

13. Firlik KS, Kondziolka D, Flickinger JC, Lunsford LD (2000) Stereotactic radiosurgery for brain metastases from breast cancer. Ann Surg Oncol 7:333-338

14. Gadducci A, Tana R, Teti G, Fanucchi A, Pasqualetti F, Cionini L, Genazzani AR (2007) Brain recurrences in patients with ovarian cancer: report of 12 cases and review of the literature. Anticancer Res 27:4403-4409

15. Geisler JP, Geisler HE (1995) Brain metastases in epithelial ovarian carcinoma. Gynecol Oncol 57:246-249

16. Jawahar A, Matthew RE, Minagar A, Shukla D, Zhang JH, Willis BK, Ampil F, Nanda A (2004) Gamma knife surgery in the management of brain metastases from lung carcinoma: a retrospective analysis of survival, local tumor control, and freedom from new brain metastasis. J Neurosurg 100:842-847

17. Jemal A, Siegel R, Xu J, Ward E (2010) Cancer statistics, 2010. CA Cancer J Clin 60:277-300

18. Kaminsky-Forrett MC, Weber B, Conroy T, Spaeth D (2000) Brain metastases from epithelial ovarian carcinoma. Int $\mathrm{J}$ Gynecol Cancer 10:366-371

19. Kawana K, Yoshikawa H, Yokota H, Onda T, Nakagawa K, Tsutsumi O, Taketani Y (1997) Successful treatment of brain metastases from ovarian cancer using gamma-knife radiosurgery. Gynecol Oncol 65:357-359

20. Kim TJ, Song S, Kim CK, Kim WY, Choi CH, Lee JH, Lee JW, Bae DS, Kim BG (2007) Prognostic factors associated with brain metastases from epithelial ovarian carcinoma. Int $\mathrm{J}$ Gynecol Cancer 17:1252-1257

21. Kolomainen DF, Larkin JM, Badran M, A'Hern RP, King DM, Fisher C, Bridges JE, Blake PR, Barton DP, Shepherd JH, Kaye SB, Gore ME (2002) Epithelial ovarian cancer metastasizing to the brain: a late manifestation of the disease with an increasing incidence. J Clin Oncol 20:982-986

22. Kumar L, Barge S, Mahapatra AK, Thulkar S, Rath GK, Kumar S, Mishra R, Dawar R, Singh R (2003) Central nervous system metastases from primary epithelial ovarian cancer. Cancer Control 10:244-253

23. Lederman G, Wronski M, Fine M (2001) Fractionated radiosurgery for brain metastases in 43 patients with breast carcinoma. Breast Cancer Res Treat 65:145-154

24. Lee YK, Park NH, Kim JW, Song YS, Kang SB, Lee HP (2008) Gamma-knife radiosurgery as an optimal treatment modality for brain metastases from epithelial ovarian cancer. Gynecol Oncol 108:505-509

25. LeRoux PD, Berger MS, Elliott JP, Tamimi HK (1991) Cerebral metastases from ovarian carcinoma. Cancer 67:2194-2199

26. McMeekin DS, Kamelle SA, Vasilev SA, Tillmanns TD, Gould NS, Scribner DR, Gold MA, Guruswamy S, Mannel RS (2001) Ovarian cancer metastatic to the brain: what is the optimal management? J Surg Oncol 78:194-201

27. Melichar B, Urminska H, Kohlova T, Nova M, Cesak T (2004) Brain metastases of epithelial ovarian carcinoma responding to cisplatin and gemcitabine combination chemotherapy: a case report and review of the literature. Gynecol Oncol 94:267-276

28. Monaco E 3rd, Kondziolka D, Mongia S, Niranjan A, Flickinger JC, Lunsford LD (2008) Management of brain metastases from ovarian and endometrial carcinoma with stereotactic radiosurgery. Cancer 113:2610-2614

29. Mori Y, Kondziolka D, Flickinger JC, Logan T, Lunsford LD (1998) Stereotactic radiosurgery for brain metastasis from renal cell carcinoma. Cancer 83:344-353

30. Muacevic A, Kreth FW, Horstmann GA, Schmid-Elsaesser R, Wowra B, Steiger HJ, Reulen HJ (1999) Surgery and radiotherapy compared with gamma knife radiosurgery in the treatment of solitary cerebral metastases of small diameter. J Neurosurg 91:35-43

31. Muacevic A, Kreth FW, Tonn JC, Wowra B (2004) Stereotactic radiosurgery for multiple brain metastases from breast carcinoma. Cancer 100:1705-1711

32. O’Neill BP, Iturria NJ, Link MJ, Pollock BE, Ballman KV, O'Fallon JR (2003) A comparison of surgical resection and stereotactic radiosurgery in the treatment of solitary brain metastases. Int J Radiat Oncol Biol Phys 55:1169-1176

33. Pan HC, Sheehan J, Stroila M, Steiner M, Steiner L (2005) Gamma knife surgery for brain metastases from lung cancer. J Neurosurg 102(Suppl):128-133

34. Pectasides D, Aravantinos G, Fountzilas G, Kalofonos C, Efstathiou E, Karina M, Pavlidis N, Farmakis D, Economopoulos T, Dimopoulos MA (2005) Brain metastases from epithelial ovarian cancer. The Hellenic Cooperative Oncology Group (HeCOG) experience and review of the literature. Anticancer Res 25:3553-3558

35. Pectasides D, Pectasides M, Economopoulos T (2006) Brain metastases from epithelial ovarian cancer: a review of the literature. Oncologist 11:252-260

36. Pothuri B, Chi DS, Reid T, Aghajanian C, Venkatraman E, Alektiar K, Bilsky M, Barakat RR (2002) Craniotomy for central nervous system metastases in epithelial ovarian carcinoma. Gynecol Oncol $87: 133-137$ 
37. Rodriguez GC, Soper JT, Berchuck A, Oleson J, Dodge R, Montana G, Clarke-Pearson DL (1992) Improved palliation of cerebral metastases in epithelial ovarian cancer using a combined modality approach including radiation therapy, chemotherapy, and surgery. $\mathrm{J}$ Clin Oncol 10:1553-1560

38. Sheehan JP, Sun MH, Kondziolka D, Flickinger J, Lunsford LD (2002) Radiosurgery for non-small cell lung carcinoma metastatic to the brain: long-term outcomes and prognostic factors influencing patient survival time and local tumor control. J Neurosurg 97:1276-1281

39. Sheehan JP, Sun MH, Kondziolka D, Flickinger J, Lunsford LD (2003) Radiosurgery in patients with renal cell carcinoma metastasis to the brain: long-term outcomes and prognostic factors influencing survival and local tumor control. J Neurosurg 98:342-349

40. Shuto T, Inomori S, Fujino H, Nagano H (2006) Gamma knife surgery for metastatic brain tumors from renal cell carcinoma. J Neurosurg 105:555-560

41. Therasse P, Arbuck SG, Eisenhauer EA, Wanders J, Kaplan RS, Rubinstein L, Verweij J, Van Glabbeke M, van Oosterom AT, Christian MC, Gwyther SG (2000) New guidelines to evaluate the response to treatment in solid tumors. European Organization for Research and Treatment of Cancer, National Cancer Institute of the United States, National Cancer Institute of Canada. J Natl Cancer Inst 92:205-216
42. Watanabe A, Shimada M, Kigawa J, Iba T, Oishi T, Kanamori Y, Terakawa N (2005) The benefit of chemotherapy in a patient with multiple brain metastases and meningitis carcinomatosa from ovarian cancer. Int J Clin Oncol 10:69-71

\section{Comment}

This is an important paper on radiosurgery for brain metastases caused by ovarian cancer. Brain metastases caused by ovarian cancer are rare. Yet, with improving oncological care, they are encountered more frequently. Not surprisingly, the results following radiosurgery for those brain metastases are comparable to the results for brain metastases caused by other carcinomas. Local tumor control following radiosurgery for brain metastases seems to be independent of tumor histology, whereas survival seems to depend on tumor histology and progression of the systemic disease [1].

1. Mindermann T (2005) Tumor recurrence and survival following gamma knife surgery for brain metastases. J Neurosurg (Suppl) 102:287-288

Thomas Mindermann

Zurich, Switzerland 